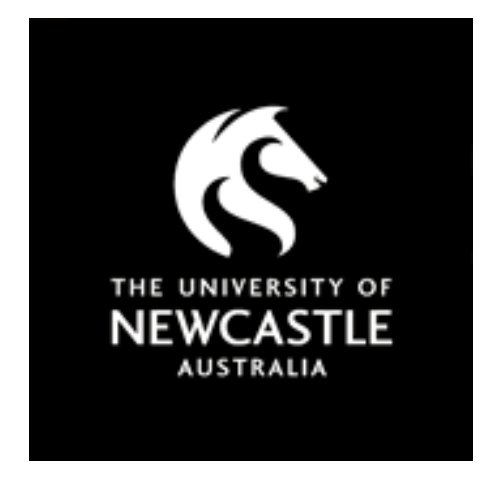

NOVA

University of Newcastle Research Online

nova.newcastle.edu.au

Lynagh, Marita C.; Sanson-Fisher, Rob W.; Bonevski, Billie " What's good for the goose is good for the gander. Guiding principles for the use of financial incentives in health behaviour change". Originally published in International Journal of Behavioral Medicine Vol. 20, Issue 1, p. 114-120

Available from: http://dx.doi.org/10.1007/s12529-011-9202-5

The final publication is available at www.springerlink.com

Accessed from: http://hdl.handle.net/1959.13/1067861 
Manuscript Title:

What's good for the goose is good for the gander.

Guiding principles for the use of financial incentives

in health behaviour change.

Authors:

Marita C Lynagh

School of Medicine \& Public Health

University of Newcastle, Australia

Rob W Sanson-Fisher

School of Medicine \& Public Health

University of Newcastle, Australia

\section{Billie Bonevski}

Centre for Health Research \& Psycho-oncology (CHeRP)

University of Newcastle, Australia

Running head: Financial incentives \& health behaviour change

Requests for reprints addressed to:

Marita C Lynagh

PhD, Grad Dip Hlth Prom, BHMS (Hons)

Senior Lecturer

School of Medicine \& Public Health

University of Newcastle

David Maddison Building

Cnr King \& Watt Streets

Newcastle NSW 2300

Australia

Email: Marita.Lynagh@newcastle.edu.au

Word Count $=3,578$ 


\begin{abstract}
Background: The use of financial incentives or Pay-for-Performance programs for health care providers has triggered emerging interest in the use of financial incentives for encouraging health behaviour change.

Purpose: This paper aims to identify key conditions under which the use of financial incentives for improvements in public health outcomes are most likely to be effective and appropriate.
\end{abstract}

Methods: We review recent systematic reviews on their effectiveness in changing health behaviour and identify existing moral concerns concerning personal financial incentives.

Results: Current evidence indicates that incentives can be effective in driving health behaviour change under certain provisos, while a number of misgivings continue to be deliberated on. We outline a number of key principles for consideration in decisions about the potential use of incentives in leading to public health improvements.

Conclusion: These key principles can assist policy makers in making decisions on the use of financial incentives directed at achieving improvements in public health.

Key words: financial incentives, health behaviour, rewards, contingency management 


\section{Introduction}

The recent proliferation of 'Pay-for-Performance' (P4P) programs for health care providers has triggered growing interest in the use of personal financial incentives $(\mathrm{PFI})$ to encourage people to change unhealthy behaviours and increase use of preventive health services, also known as 'Pay-for-Performance-for-Patients' (P4P4P).(1) Incentives in the form of financial rewards and vouchers have long been demonstrated to be effective in treating in-patient substance users. $(2,3)$ Outside of the clinical setting, they have been utilised by health insurers in the United Kingdom and the USA to encourage individuals to engage in health promoting behaviours, such as exercise, quitting smoking and screening programs.(4) Since 1998 the Oportunidades conditional cash transfer (CCT) program in Mexico has seen families receive cash payments in exchange for complying with attendance at a range of preventive health care services and school attendance for children.(5) In Canada, the Children's Fitness Tax Credit scheme was introduced in 2007, providing parents with up to CAN\$500 per eligible child to cover enrolment fees in physical activity programs.(6) In Australia, the federal government have successfully used P4P4P (for parents) together with $\mathrm{P} 4 \mathrm{P}$ (the General Practitioner Immunisation Incentive Scheme) to increase child immunisation rates from 56\% in 1996 to $90 \%$ in 2003 (7) and the introduction of the national Baby Bonus Scheme in July 2004 led to a significant rise in fertility rates. (8)

Previous reviews $(2,3,9)$ have indicated that PFI can be effective in promoting healthy behaviour though studies included in these reviews have tended to target clinical behaviours such as compliance with medication regimes or substance abuse treatment. This evidence combined with recent initiatives described above suggest 
that the application of PFI to more common lifestyle health behaviours and large population based trials is a new and promising field of investigation. Importantly, there is a need to understand the optimal conditions for applying PFI to achieve behaviour change with minimal adverse consequences. In 2009, the Tobacco Working Group of the National Preventative Taskforce in Australia (10) strongly recommended that $\mathrm{PFI}$ schemes for smoking cessation be trialled. Further evidence and debate is undoubtedly necessary for the application of PFI to smoking and a range of other health risk behaviours. For while incentive programs for doctors are now considered more or less conventional, there remains considerable misgivings over their appropriateness and effectiveness with patients or the general population.(11) Is it a case of what's good for the goose is good for the gander? The answer appears to be multifaceted and equivocal.

\section{Purpose}

The aim of this paper is to review both the effectiveness of PFI for health behaviour change in general populations and associated moral considerations, and propose a number of key guiding principles to assist policy makers in making decisions on the use of PFI directed at achieving improvements in public health.

\section{Method}

The paper draws on evidence from a selective, non-systematic review of recent literature. Primarily, the review focuses on the outcomes and messages gleaned from several key published literature reviews including the Cochrane(12) and Leeks et al (13) systematic reviews of competitions and incentives for smoking cessation, King's Fund(14) and QQUIP reviews(15) of paying the patients, the Australian National 
Health and Hospitals Reform Commission report,(16) the Lagarde(17) review and World Bank report(18) on conditional cash transfers, $(17,18)$ and other systematic reviews on weight loss. (19) The paper focuses on recent evidence so although 32 systematic reviews on the effectiveness of $\mathrm{FI}$ in changing health behaviour have been conducted, we have considered only those published in the last 5 years. The paper also focuses on patient and/or population paid incentives so articles describing health care provider payments have been excluded. In addition to examination of relevant reviews, an electronic search of the Medline and PubMed databases was conducted for recent articles reporting on the latest research evidence, opinions and debate around patient financial incentives. These papers were considered valuable in providing insight for the current narrative review.

\section{Effectiveness of incentives}

Evidence from the most recent systematic reviews of the effectiveness of PFI (12-19) indicates that PFI can be effective in driving behaviour change, however, this is tempered by a number of provisos. First, in regard to the types of behaviours likely to be influenced, incentives by themselves appear most effective in altering behaviours which are simple, discrete and time-limited such as take-up of immunisations and attendance at health and education services, and less effective for complex and entrenched behaviours such as smoking, diet and exercise.(14-16, 18) Recent studies, which were not included in any of the systematic reviews, however provide some evidence that when supported with other intervention strategies such as social support and skill training, PFI can be effective in changing more complex behaviours such as reducing smoking $(20,21)$ and leading to weight loss.(22) 
Second, population socio-economic characteristics appear to be important with socially disadvantaged groups being the most amenable,(15, 17) especially when incentives are viewed as addressing the real or perceived economic barriers to change such as transport, medication and child-care costs.(14) Evidence from reviews of conditional cash transfer (CCT) programs that have largely been conducted in Latin America and developing nations in Asia and Africa indicate substantial improvements to use of preventive health services, attendance at schools and reduced poverty, but findings relating to the "final" health and education-related outcomes are mixed.(17, 18) Few studies have targeted non-disadvantaged populations. Volpp's(20) randomised controlled trial of incentives for smoking cessation in 878 employees at a multinational company in the US is one of the few, producing strong evidence for the effectiveness of incentives in a middle-income group.(22)

Third, current reviews conclude that there is little evidence for the long-term sustainability of effects once the incentive is withdrawn. This represents a key challenge to the viability of incentive-based programs. Recent research however has produced promising findings that effects can persist. Volpp's(20) randomised controlled trial (mentioned above) found incentive groups had significantly higher quit rates at 6,9 and 12 months after enrolment in the study with a significant difference maintained at 6 months after rewards were withdrawn. The authors of this trial argue that previous conclusions of reviews were erroneous because of insufficient sample size to detect differences at follow-up.(20) Additionally, results of a non-randomised trial by Higgins et al on the use of voucher-based incentives to smoking abstinence in pregnant women found indicated that quit rates remained significantly higher in the 
contingent group after the discontinuation of rewards at 24 weeks postpartum.(23) A more recent randomised controlled trial by the same researchers however failed to repeat the significant follow-up finding as the earlier trial, though abstinence rates remained greater.(21) There is evidence in the literature on clinical substance use treatment programs $(24,25)$ for the effectiveness of a 'maintenance incentive contingency' beyond the initial reward treatment phase, yet this approach does not appear to have been adopted or evaluated outside the clinical setting for other health-related behaviours.

The relationship between FI and behaviour change is not a simple one but appears to be influenced by the complexity of the target behaviour, population characteristics and potentially other unidentified variants. While questions remain concerning effectiveness in non-disadvantaged groups and long-term sustainability, PFI do hold promise as an effective means for changing health behaviours, albeit with some qualifications.

\section{Moral concerns}

Two potential 'unintended consequences' relate to the effect that FI may have on the trust inherent in the doctor-patient relationship and patient autonomy.(11) Some view the use of rewards for patients as bribery or coercion, while others perceive it as acceptable and less time-consuming than traditional methods of behaviour change, and more likely to be adopted into practice.(2) Marteau et al(11) contend that FI may augment rather than constrain patient autonomy by aligning actual behaviour ("first order desires") with preferred actions ("second order desires"). Put more simply, 
people often act in ways that, upon reflection, they wish they had not. Incentives can increase the likelihood that people will choose what is best for their long-term interests. Thaler and Sunstein (26) would describe this as an acceptable "nudge" in the right direction, yet others view it as an unacceptable "shove".(27) One way to better understand and resolve this 'dilemma' may be to consider a behavioural economics perspective.

Economic theory has long maintained that people do not always think or behave as expected or in a rational way,(28) and evidence from across the behavioural sciences has provided a growing knowledge base of the many factors that influence our behaviour, some of which we have no awareness of control of. The MINDSPACE program(29, 30) developed by the Institute for Government in the UK uses this knowledge base to provide a tool to assist policy-makers in their decisions about health interventions. Drawing upon the most 'robust' influences on human behaviour and behaviour change, the program creators argue that "the government's involvement in changing behaviour is not mutually exclusive with personal responsibility." (30) The assertion is that providing the carrot to make an initial change to behaviour will enable people to then build on that change and take greater personal responsibility for maintaining behaviour.(30) Behavioural economists espouse the notion that it is beneficial to all that environments and circumstances be configured (for example, through the provision of incentives) to enable better health choices, while not replacing or diminishing individual autonomy.(31) We support this tenet and propose that under certain conditions, incentives can be an acceptable form of persuasion, particularly for shaping and encouraging initial behaviour change. 
Though no direct evidence exists in public health research, some studies in psychology have shown that FI can undermine people's intrinsic motivation.(14) A meta-analysis of 128 laboratory experiments found that tangible rewards had a substantial negative effect on intrinsic motivation. (32) Health economists describe this phenomenon as "crowding out". External rewards impair self-esteem and shift the locus of control leading to the displacement of internal motivation by the external incentive.(33) Social psychologists and Self-Determination Theory argue that behaviour change motivated by intrinsic drive is more preferable than that motivated by extrinsic rewards as it improves the quality of behaviour and sense of wellbeing.(34) However, others have questioned this belief. For instance, researchers examining neurological brain activation in participants performing simple tasks under different motivation conditions report overlapping and shared neural pathways between intrinsic and extrinsic motivation situations.(35) Additionally, qualitative research on the impact of pay-for-performance in primary care practices indicates that financial incentives have had little damage on the internal "moral" motivation of general practitioners.(36) While it appears that the impact of $\mathrm{FI}$ on internal motivation for health behaviour change is at present unclear and does warrant further investigation, perhaps equally important is determining whether certain population groups will or can ever be internally motivated to engage in health promoting behaviour. We suspect not. There may also be situations where simple, immediate or short-term behaviour, such as uptake of immunisations, results in a direct improvement to health outcomes for which the form of motivation (intrinsic vs extrinsic) is inconsequential. 
Perhaps the issue of greatest concern lies with fairness and whether public funds should be used to pay some people to change their behaviour when others manage to do so without any financial reward. $(1,11)$ This again relates to the issue of personal responsibility discussed above and the question of who is responsible for health behaviour? This has long been a matter of academic and public debate. Evidence relating to public opinion suggests that in general, most people hold the view that individuals are responsible for their own health and well-being and hence should bear the costs of their self-inflicted morbidity.(30) Early exploration of the philosophical implications of holding individuals responsible for their own poor health choices by Dworkin(37) and Wikler(38) however strongly challenge this belief. Now considered landmark papers, they provide compelling arguments which give recognition to social and health inequalities, injustice, human rights and social responsibility. $(37,38)$ We argue that the use of incentives targeted at vulnerable populations or socially disadvantaged groups is a 'fair' and 'just' intervention as it actually addresses health inequalities.

It is also interesting to note that while people consider that they should be responsible for making their own decisions regarding their health, they equally believe that the government has a duty to intervene in ways that promote and encourage healthy behaviour.(30) Little is known about public opinion of the 'fairness' or acceptability of the use of incentives to encourage healthy lifestyles, with only two studies $(39,40)$ conducted to-date. In the first of these, patients attending primary care clinics in the US are equivocal about the use of financial rewards to promote smoking cessation, weight loss and improved management of high blood pressure and blood sugar levels.(39) A more recent study on the acceptability of incentives for 
encouraging pregnant women to quit smoking found low support for the scheme.(40) While it is important that we consider people's views about the "fairness" of incentives, lack of public acceptability should not be a criterion for precluding further research in this area.

From a health economics perspective and given the significant health burden associated with unhealthy lifestyles, it is also reasonable to ask - is it not better to pay now than pay later? Public money is already used to fund initiatives for persuading people to quit smoking, do more exercise and eat better, but currently that funding is channelled through the health care system via P4P programs, patient education, mass media and other health promotion interventions. Rarely are the costs for these initiatives questioned or considered unjust. Incentives have an added advantage of providing direct rather than channelled funding to assist those people motivated to change their behaviour. We argue that any possible ideological misgivings about the fairness of PFI should be further weighed against the potential health and economic benefits of such.

\section{Guiding principles for use of personal financial incentives}

The principles outlined below attempt to provide practical guidelines to assist policy makers and public health organisations in making decisions about the likely effectiveness and appropriateness of incentives for health behaviour change. The principles derive from empirical evidence and/or relevant theoretical frameworks. Any decision about the use of PFI should be evidence-based and involve rigorous evaluation of both efficacy and effectiveness in promoting positive behaviour change. Additionally, longer term monitoring is needed to demonstrate that PFI can lead to 
improved public health outcomes. The decision to use PFI should only be made when evidence of positive health behaviour change and related outcomes are seen to outweigh the potential risks or other moral concerns.

\section{1. 'Good' measures of behaviour}

Pivotal to operant learning theory and contingency management, financial incentives should only be used when there are reliable, accurate and acceptable measures of behaviour change.(2) Uptake of immunisations, participation in treatment and screening programs are obvious applications, but other less apparent health behaviours may still satisfy this principle such as smoking cessation (biochemical validation) and physical activity (pedometers validation). Incentive schemes targeting more 'complex' behaviours should be used in combination with other supportive strategies such as patient education, skills training and social support.(20, 22) FI may also be offered for behaviours considered important "stepping stones" in indicating potential for successful health risk behaviour change.(15)

\section{High risk population groups}

Incentive programs are likely to be more effective with disadvantaged or vulnerable populations, $(14,15)$ however this should not preclude further investigation of their potential with the general population for whom success may be more closely linked to the size of the incentive. Because of their likely associated high costs, incentives should also be considered for use for 'high risk' groups who may be difficult to reach or who under-utilise existing health services.(16) 


\section{Incentives that are sufficient in size}

Though low value incentives have shown some success, magnitude is important with the greater the reward the greater the effect, indicating a dose-response relationship.(15) For example, a higher proportion of patients who received $\$ 10$ made a return visit to a tuberculosis clinic compared to patients who received $\$ 5$ or no incentive.(41) In contrast, middle-class employees in a recent smoking cessation trial were eligible to receive FI totalling US\$750 for 6 months continuous abstinence.(20) The size of the incentive is in part dependent upon population socioeconomic characteristics, thus a person's 'marginal utility of money'.(16) This means that a quantity of money (eg. $\$ 20$ dollars) is worth more to some people than others (usually people on low incomes in comparison to higher incomes.(16) Incentive magnitude will also depend on the opportunity costs incurred by the behaviour change. That is, whether the costs (such as time, money, resources, effort etc) associated with behaviour change outweigh the expected benefits.(16) How should we determine then what value of incentive is firstly sufficient and second, most costeffective? In regard to sufficiency, the review on incentives in treatments for obesity and overweight reported a weak trend of more favourable results with incentives greater than $1.2 \%$ of personal disposable income.(19) In general, there is a lack of research to inform the determination of adequate incentive amount for particular behaviours in specific population groups.

The same can be said in regard to determining cost-effectiveness. One option is to consider the comparative costs involved in implementing other more intensive public health interventions such as mass media campaigns, patient education and $\mathrm{P} 4 \mathrm{P}$ 
programs for health care providers. Incentive-based programs should be viewed as another 'level' within a multi-level intervention approach and complementary to these more traditional initiatives. It has been suggested that both low intensity, low cost interventions with greater reach and higher intensity, higher cost initiatives with lower reach have an important and valuable role to play.(21)

\section{Frequent \& incremental reinforcement schedule with reset contingency}

Equally important as the magnitude of the incentive is the pattern of reinforcement schedule under which it is provided. While 'one-off' incentive payments may be sufficient to impact simple 'one-off' behaviours, such as uptake of immunisation or attendance for a health screening test, more complex behaviours require a carefully measured schedule of incentives to both initiate and maintain behaviour change. Evidence is compelling from both drug treatment programs $(2,25,42)$ and smoking cessation trials(21) that schedules which incorporate an escalating size of incentive with frequent monitoring and rewards are most effective at producing positive outcomes. This is particularly important for behaviours where maintaining an initial period of change is critical to sustaining longer term change (eg. smoking abstinence).(43) Incentives should be provided frequently during the initial period of abstinence with rewards increasing in magnitude for consecutive blocks of abstinence and then diminish in frequency. $(21,25)$ Additionally, the reinforcement schedule should include a reset contingency wherein a relapse in behaviour resets the size of the incentive to its initial value. $(21,25)$ At least in regard to substance use treatment, the combination of all three elements have demonstrated superiority over all other scheduling arrangements. 


\section{Minimal delay between behaviour and reward}

The closer the reward is given to the time of the behaviour the more likely it is to be effective. $(1,15,16)$ Immediacy is another important variable central to operant learning theory and contingency management.(2) Though few studies have rigorously evaluated the impact of timing, evidence from drug treatment programs indicate that those which provide immediate rewards are more successful than those in which rewards are delayed.(44) Ideally, incentives should be implemented and administered by health care providers on-site and without delay. Where validation of behaviour requires more invasive and lengthier measurement, then an 'interim' reward should be provided more immediately as positive reinforcement.

\section{Carrots are better than sticks}

In general, evidence suggests that 'negative' incentives or penalties are less effective than rewards or 'positive incentives'.(14, 15) It is believed that 'sticks' reinforce personal failure and rather than building competency, they confirm low expectations about the self.(2) Further, financial penalties may be viewed as punishing those who are most vulnerable.(16)

Finally these principles are offered with some caveats. Consideration of the limitations of the data from which these recommendations are drawn needs to be made. In particular, most of the available evidence is drawn from research conducted in the United States or United Kingdom. The public health policies and health systems of these countries, as well as other environmental influences such as health insurance systems and welfare programs, are vastly different to those operating in many other parts of the world. The relevance of this data to the local context for 
decision makers is questionable. For example, much of the evidence regarding incentive size necessary to affect change stems from US based studies were the PFI is used to defray costs associated with accessing health care. Research and data obtained from other countries on the use of financial incentives is urgently needed. The guiding principles presented here are based on literature selected in order to support arguments rather than on a systematic review. Although a selective review provides valuable insights that a systematic review would not have included, the limitations with the quality of research included should be borne in mind.

In conclusion, a growing need remains for effective interventions that can readily be adopted into routine clinical practice and public health policy to encourage health behaviour change, producing improved health outcomes for populations and a reduced burden on health care systems. Financial incentives are not the panacea to all health risk behaviours but do hold promise for encouraging certain population groups to modify particular health behaviours. Future use of PFI in public health will depend on the presence or absence of several criteria and as such, requires careful consideration of the principles described here rather than a 'one-size-fits-all' approach. What's good for the goose may be even better for the gander. 


\section{References}

1. Volpp KG, Pauly MV, Loewenstein G, Bangsberg D. P4P4P: An agenda for research on pay-for-performance for patients. Health Aff. 2009;28(1):206-14.

2. Petry NM. A comprehensive guide to the application of contingency management procedures in clinical settings. Drug Alcohol Depend. 2000;58:9-25.

3. Prendergast M, Podus D, Finney J, Greenwell L, Roll J. Contingency management for treatment of substance use disorders: a meta-analysis. Addiction. 2007;101:1546-60.

4. Greene J. Medicaid Efforts to Incentivize Healthy Behaviours. New Jersey: Center for Health Care Systems.2007.

5. $\quad$ Fernald L, Gertler P, Neufeld L. Role of cash in conditional cash transfer programmes for child health, growth and development: an analysis of Mexico's Oportunidades. Lancet. 2008;371:828-37.

6. Report of the Expert Panel for the Children' Fitness Tax Credit. Ottawa, Ontario.: Department of Finance Canada2006.

7. The Royal Australian College of General Practitioners (RACGP). Immunisation Position Paper. Melbourne, Vic.: RACGP.2003.

8. Gray M, Qu L, Weston R. Fertility and Family Policy in Australia. Canberra, Australia: Australian Instititute of Family Studies.2006.

9. Lussier JP, Heil SH, Mongeon JA, Badger GJ, Higgins ST. A meta-analysis of voucher-based reinforcement therapy for substance use disorders. . Addiction. 2006;101(2):192-203.

10. National Preventative Health Taskforce. Tobacco Control in Australia: Making Smoking History.2009.

11. Marteau TM, Ashcroft RE, Oliver A. Using financial incentives to achieve healthy behaviour. BMJ. 2009;338:1415.

12. Cahill K, Perera R. Competitions and incentives for smoking cessation. Cochrane Database of Systematic Reviews. 2008(Issue 3).

13. Leeks KD, Hopkins D, Soler R, Aten A, Chattopadhyay S. Worksite-based incentives and competitions to reduce tobacco use. A systematic review. American Journal of Preventive Medicine. 2010;38:S263-S74.

14. Jochelson K. Kicking bad habits. Paying the patient. Improving health using financial incentives. London, UK.: King's Fund.2007.

15. Sutherland K, Leatherman S, Christianson J. Paying the patient: does it work? A review of patient-targeted incentives. London: QQUIP. Quest of Quality and Improved Performance. The Health Foundation.2008.

16. Scott A, Schurer S. Financial incentives, personal responsibility and prevention. Canberra,: Discussion paper commissioned by the National Health and Hospitals Reform, Australian Government.2008.

17. Lagarde M, Haines A, Palner N. Conditional Cash Transfers for improving uptake of health interventions in low- and middle-income countries. JAMA. 2007;298(16):1900-10.

18. Fiszbein A, Schady N. Conditional Cash Transfers. Reducing present and future poverty. Washington, D.C.: The World Bank.2009.

19. Paul-Ebhohimhen V, Avenell A. Systematic review of the use of financial incentives in treatments for obesity and overweight. Obesity Reviews. 2008;9:355-67.

20. Volpp KG, Troxel AB, Pauly MV, Glick HA, Puig A, Asch DA, et al. A randomized, controlled trial of financial incentives for smoking cessation. N Engl J Med. 2009;360:699709. 
21. Heil S, Higgins S, Bernstein I, Soloman L, Rogers R, Thomas C, et al. Effects of vouhcer-based incentives on abstinence from cigarette smoking and feral growth among pregnant women. Addiction. 2008;103:1009-18.

22. Volpp KG, John L, Troxel A, Norton L, Fassbender J, Lowenstein G. Financial incentive-based approaches for weight loss. A randomised trial. JAMA. 2008;300:2631-37.

23. Higgins S, Heil S, Soloman L, Plebani Lussier J, Abel R, Lynch M, et al. A pilot study on voucher-based incentives to promote abstinence from cigarette smoking during pregnancy and postpartum. Nicotine \& Tobacco Research. 2004;6:1015-20.

24. Preston K, Umbricht A, Epstein D. Abstinence reinforcement maintenance contingency and one-year follow-up. Drug and Alcohol Dependence. 2002;67:125-37.

25. Roll J, Huber A, Sodano R, Chudzynski J, Moynier E, Shoptaw S. A comparison of five reinforcement schedules for use in contingency management-based treatment of methamphetamine abuse. The Psychological Record. 2006;56:67-81.

26. Thaler RH, Sunstein CR. Nudge. Improving decisions about health, wealth and happiness. Camberwell, Australia: Penguin Books.; 2009.

27. Marteau TM, Oliver A, Ashcroft RE. Changing behaviour through state intervention. When does an acceptable nudge become an unacceptable shove? BMJ. 2009;338:121-2.

28. Kahneman D, Tversky A. Prospect theory: an analysis of decision under risk. Econometrica. 1979;47:263-91.

29. Vlaev I, Dolan P. From changing cognitions to changing the context: a dual-route model of behaviour change/. London: Imperial College London Business School2009.

30. Dolan P, Hallsworth M, Halpern D, King D, Vlaev I. MINDSPACE. Influencing behaviour through public policy. United Kingdom.: Institute for Government,; 2010; Available from: www.instituteforgovernment.org.uk.

31. Klein E, Karlawish J. Challenges and opportunities for developing and implementing incentives to improve health-related behaviours in older adults. Journal of American Geriatrics Society. 2010;58:1758-63.

32. Deci EL, Koestner R, Ryan RM. A meta-analytic review of experiments examining the effects of extrinsic rewards on intrinsic motivation. Psychological Bulletin. 1999;125:62768.

33. Frey B, Jegen R. Motivation crowding theory. Journal of Economic Surveillance. 2001;15:590-611.

34. Ryan R, Deci E. Self-determination theory and the facilitation of intrinsic motivation, social development, and well-being. American Psychologist. 2000;55:68-78.

35. Lee W, Reeve J, Xue Y, Xiong J. Similarities and differences in the neural activities of intrinsic motivation and incentive motivation. NeuroImage. 2009;47(Supplement 1):S39S41.

36. McDonald R, Harrison S, Checkland K, Campbell S, Roland M. Impact on financial incentives on clinical autonomy and internal motivation in primary care: ethnographic study. BMJ. 2007;334(7608):1357-62.

37. Dworkin G. Taking RIsks, Assessing Responsbility. The Hastings Center Report. 1981;11:26-31.

38. Wikler D. Who should be blamed for being sick? Health Education Quarterly. 1987;14:11-25.

39. Long JA, Helweg-Larsen M, Volpp KG. Patient opinions regarding 'pay for peformance for patients'. J Gen Intern Med. 2008;23(10):1647-52.

40. Lynagh M, Bonevski B, Symonds I, Sanson-Fisher RW. Paying pregnant women to quit smoking during pregnancy? Acceptability among pregnant women. Nicotine \& Tobacco Research. 2011:(in press). 
41. Malotte CK, Rhodes F, Mais KE. Tuberculosis screening and compliance with return for skin test reading among active drug users. Am J Public Health. 1998;88:792-6.

42. Ghitza U, Epstein D, Schmittner J, Vahabzadeh M, Lin JL, Preston K. Effect of reinforcement probabilty and prize size on cocaine and heroin abstinence in prize-based contingency management. Journal of Applied Behaviour Analysis. 2008;41:539-49.

43. Higgins S, Badger G, Budney A. Initial abstinence and success in achieving longerterm cocaine abstinence. Exp Clin Psychopharmacol. 2000;8:377-86.

44. Petry N, Casarella T. Excessive discounting of delayed rewards in substance abusers with gambling problems. Drug and Alcohol Dependence. 1999;56:25-32. 